\title{
En torno a Utrecht y Aquisgrán: el pensamiento político-económico español sobre asiento de negros y navío de permiso (1701-1750)/
}

\author{
Around Utrecht and Aquisgrán: \\ the Spanish political-economic thought \\ on «asiento de negros» and «navío de permiso» \\ (1701-1750)
}

José Miguel Delgado Barrado

Universidad de Jaén

El trabajo tiene tres claros objetivos. Primero, la necesidad de aplicar perspectivas comparadas, interdisciplinares y de larga duración; segundo, replantear la hipótesis de la inexistencia de un pensamiento político y económico de los escritores españoles sobre el tráfico de negros y el navío de permiso en España; y tercero, establecer coyunturas de interés suscitadas por estos temas en España, especialmente en años clave como 1725-1727 y el pensamiento político-económico, más o menos continuo, hasta el desenlace de 1750.

Palabras Clave: Historia Moderna; Siglo XVIII; España; América Española; Utrecht; Aquisgrán; Comercio Colonial; Asiento de Negros; Navío de Permiso; Pensamiento Político; Pensamiento Económico

The work has three clearly objectives. First, the necessity to apply a new compared perspective, interdisciplinary view and long terms; second, to reconsider the hypothesis of the non existence of a political and economic thought of the Spanish writers on the "asiento de negros» and the "navio de permiso» in Spain; and third, to establish interesting conjunctures, specially between 1725 and 1727, the more or less continuous political-economic thought until 1750.

KeYwords: Modern History; XVIII Century; Spain; Spanish America; Utrecht; Aquisgran; Colonial Trade; Asiento de Negros; Navío de Permiso; Political Thought; Economic Thought 


\section{Planteamiento y posicionamiento inicial}

La compleja historia del asiento de negros y navío de permiso durante el siglo XVIII nos confirma la necesidad de afrontar y exprimir al máximo todos y cada uno de los aspectos que conforman estos acontecimientos históricos.

El análisis debe obligatoriamente pasar por la observancia de un escrupuloso método histórico donde las relaciones entre coyunturas y estructuras, distintos niveles de actuación, los planos teóricos y prácticos, se den la mano con los protagonistas de los acontecimientos, la realidad nacional e internacional, el flujo comercial, los intereses de los poderosos por el control del comercio colonial, defensas y ataque del monopolio de la Carrera de Indias, etc., incluso indagar los silencios e incongruencias.

Si no establecemos un minucioso paralelismo entre coyuntura política, económica, social, cultural..., donde las claves históricas sean interpretadas a la luz de los pensamientos y las acciones, no entenderemos ni las partes ni el todo y perderemos la esencia del problema.

Y, por último, la complejidad tiene que estimular el análisis y no facilitar la simplificación. Nuestra propia ignorancia de los acontecimientos, bien por falta de fuentes documentales, por la complejidad en sí misma o por la carencia de interpretación, no debe nunca generar en unas conclusiones generalistas, ni mucho menos que éstas sean rotundas.

Nuestras hipótesis de partida pretenden ser, por el contrario, sencillas y precisas. Primero, señalar la complejidad del tema y la necesidad de perspectivas comparadas, interdisciplinares y de larga duración; segundo, replantear, reconsiderar o ajustar la hipótesis de la inexistencia de un pensamiento o reflexión política y económica de los escritores españoles sobre el tráfico de negros y el navío de permiso en España - presentando fuentes documentales inéditas o poco explotadas de ámbito nacional-; tercero, establecer coyunturas de interés — provengan de dónde provengansuscitadas por estos temas en España, especialmente en años clave como 1725-1727, la vía de negociación abierta desde 1732, el pensamiento político-económico más o menos continuo - si consideramos y metemos en paralelo los distintos espacios políticos de recepción de ideas reformistas - hasta el desenlace de 1750; y, por último, las propuestas de nuevas líneas de investigación. 


\section{De coyunturas y estructuras. De precedentes y consecuentes}

Desconocemos aún muchos de los vericuetos administrativos y burocráticos del gobierno político de la Monarquía Hispánica durante la primera mitad del siglo XVIII, ${ }^{1}$ aunque existan recientes perfiles biográficos de Felipe V y Fernando VI, ${ }^{2}$ de Isabel de Farnesio, ${ }^{3}$ de las actuaciones de algunos ministros y altos responsables políticos de la época, ${ }^{4}$ de una renovadora visión de las relaciones internacionales ${ }^{5}$ y de estudios sobre ideas y proyectos de escritores políticos y económicos. ${ }^{6}$ Sin embargo, nos falta profundizar más en el estudio de las nóminas del personal burocrático, ${ }^{7}$ de quién es quién en la administración central, ${ }^{8}$ de reinas como Bárbara de Braganza, de los cortesanos en torno a los reyes — próximos a la casa del rey, de la reina, del cuarto del príncipe de Asturias, de los infantes e infantas, etc. - ${ }^{9}$ máxime si lo comparamos con los trabajos realizados para los siglos XVI y XVII, que no me detendré a detallar.

Dadas estas lagunas es complejo establecer la cronología de los acontecimientos en torno a los debates sobre el asiento de negros y navío de permiso entre 1701 y 1750. Debemos pensar que el verdadero frente que lo envuelve todo es la crítica a una determinada presencia extranjera en España, en el comercio colonial de manera especial, y de sus mecanismos de actuación y estrategias, porque sus perjuicios para el gobierno -léase Corona- y comercio - léase Consulados- eran más que evidentes.

En muchas ocasiones las coyunturas nos hablan de vacíos documentales, pero lo que realmente sucede es que desconocemos en muchas

1 Castellano Castellano, 2004 y Delgado Barrado, 2007.

2 Martínez Shaw y Alfonso Mola, 2001, y Gómez Urdáñez, 2001.

3 Vázquez Gestal $(2013,170-187)$ realiza un excelente estudio de la cuestión historiográfica sobre la figura de Isabel de Farnesio que me exime de incluir una larga lista de obras, aunque no me resisto a señalar los trabajos de Pérez Samper, 2003 y Fragnito, 2009.

4 Para Orry, Dubet, 2005 y 2008; para Uztáriz, Fernández Durán, 1999, 2007a; para Ulloa, Fernández Durán, 2007b; para Grimaldo, Castro, 2004; para Ensenada, Gómez Urdañez, 1996; para Carvajal, Molina, 2003, Delgado Barrado, 2001; para Alsedo, Sánchez Molledo en sus ediciones de dicho autor en 2005; para Wall, Téllez, 2010; y para los ministros franceses bajo Felipe V, Desos, 2009.

5 Mur Raurell, 2011, 1.

6 Perdices y Sánchez, 2007, 53-90.

7 González Beltrán, 2005, 477.

8 Dedieu, 2011, 53-73.

9 López-Cordón, Pérez Samper y Martínez de Sas, 2000; Martínez Millán, Camarero Bullón y Luzzi Traficante, 2013; y Vázquez Gestal, 2013, 34, sólo por citar las más recientes, aunque habría que añadir aquí todas las obras sobre la Casa de Felipe V de Carlos Gómez-Centurión y Juan Antonio Sánchez Belén. 
ocasiones los vericuetos y entresijos de la administración borbónica, quiénes y cómo se realizan las tomas de decisiones políticas, y por ello no estamos buscando en los archivos o secciones adecuados. Si, como hemos dicho, los contenidos del asiento y navío están estrechamente relacionados con las críticas de la presencia extranjera en España y sus intromisiones en los negocios comerciales coloniales, también están colateralmente presentes en los asuntos de contrabando, comercio directo, aperturismo portuario, habilitaciones portuarias, compañías privilegiadas de comercio, etc. Un entramado conceptual muy amplio y difícil de presentar en todas sus variantes poliédricas, y menos de forma pormenorizada en el espacio de un artículo.

A partir de 1713, por el tratado de Utrecht, y en concreto tras el acuerdo comercial con Inglaterra del 9 de diciembre, el asiento de negros y el navío de permiso concedido, a la «nación inglesa», ${ }^{10}$ se convirtió en materia de Estado. Las mesas de negociaciones europeas ${ }^{11}$ no tenían en consideración los efectos que esta concesión pudiera tener a nivel virreinal y regnícola, como sucedía con otros cientos de asuntos que corrían paralelos dentro de las negociaciones de paz, tregua, comercio, etc., entre los Estados.

El marcado carácter internacional y diplomático marcaría un antes y un después del asiento, aunque con anterioridad a Utrecht ya existía una polémica del asiento ${ }^{12}$ - tanto por los intereses franceses como ingleses-, y que se prolongaría hasta el tratado de Aquisgrán de 1748 — cuando finalmente fue ratificado-, y comenzó a idearse el método adecuado para aniquilar la concesión, entre uno de ellos mediante una «compensación», realidad no efectiva hasta el 5 de octubre de 1750.

10 Realmente la concesión fue realizada a una compañía de comercio inglesa, creada en 1711 para tal fin. Las relaciones entre intereses del gobierno británico, la Corona y los accionistas, no siempre fue unidireccional, como veremos más adelante. Véase Frey, 1995, 17-19 y 413-415; Delgado Rivas, 2007, 88.

11 Fernández Durán $(2011,132)$ habla del protagonismo del asiento de negros en los tratados y cita el estudio legal de Gerardo Moro de 1724 (Ibidem, 377). Moro expuso sistemáticamente los perjuicios de los navíos ingleses por las internaciones de mercancías, las pérdidas en los derechos de alcabalas de los asentistas indianos y la de arrendadores de rentas reales, y ya señalaba que la concesión se había realizado «para mantener la paz y unión», véase Moro, 1724, 58.

12 Real Biblioteca del Palacio Real de Madrid (BPR), II-2822, 353-355, Noticia y razón del principio de los asientos de negros para Indias y de la Junta que se formó para entender en sus negocios, días señalados de ella y sueldos de sus empleados; según este documento el primer asiento de comercio de negros fue el 10 de enero de 1563. Archivo Histórico Nacional (AHN), Estado, lib. 779, documento 5, Sobre los perjuicios que ocasiona el asiento de negros; en este memorial, el primer asiento lo hizo Pedro Gómez Reynal el 30 de enero de 1595. Para el asiento francés del 14 de septiembre de 1701, véase Fernández Durán, 2011, 49. 
Esta realidad habría que enmarcarla en el contexto de unas coyunturas más específicas relacionadas con el comercio colonial español en América. Según Walker la intervención extranjera para conseguir un mayor grado de control en el tráfico colonial tuvo dos etapas: entre 1700 y 1713 de hegemonía francesa; y entre 1713 y 1720 de preponderancia inglesa.

Las principales vías de actuación fueron dos: entre 1700 y 1713 la intervención directa en los mecanismos internos de la Monarquía - política comercial, política interior y exterior, etc.-; y entre 1713 y 1720 con los acuerdos comerciales y diplomáticos entre las distintas potencias. Ambas vías estaban destinadas a un mismo fin: el mayor grado y mejor sistema de participación extranjera en el comercio americano.

El cambio de tendencia política detectado por Pérez-Mallaína, ya desde $1715,{ }^{13}$ y por Walker, entre 1716 y $1720,{ }^{14}$ culminaría en el Real Proyecto de Flotas y Galeones de 1720, cuyo objetivo fue mejorar y aumentar el ritmo de intercambios comerciales con América. Este proyecto de 1720 no lo podemos ver aislado de los anteriores, concretamente de las reformas del comercio colonial en 1716, 1717 y 1718, pero tampoco sería completo sin tener presentes las acciones reformistas entre 1721 y $1723 . .^{15}$

\section{Guerra, proyectos de reformas y acción política (1701-1713)}

El hecho es que, como bien sabemos, durante los años de la guerra de Sucesión entre 1701 y 1713 la península Ibérica estuvo dividida en dos centros de poder diferentes: la Corona de Castilla, defensora del candidato francés Felipe, futuro Felipe V; y la Corona de Aragón, defensora del candidato austriaco el archiduque Carlos III. ${ }^{16}$

La firma del asiento de negros del 14 de septiembre de 1701 - cuya duración se estableció por 10 años, de mayo de 1702 a mayo de 1712-

13 Pérez-Mallaína $(1982,368)$ habla de un cambio de tendencia política, ya que desde hacia tiempo existía en España una dura campaña dirigida contra los colaboradores franceses. Esto lo pone en conexión con la caída de Tinajero y Orry.

14 Walker (1979) tiene una visión clara del desarrollo de una nueva política para el comercio con las Indias a lo largo de los años 1716 a 1720.

15 Delgado Rivas, 2007, 205.

16 Frey, 1995, 95-97. 
entre Felipe V y la Francia de Luis XIV, es el acontecimiento más señalado y citado. ${ }^{17}$ Pero junto a este elemento habría que considerar otros, uno de ellos, dentro de los espacios políticos de las reformas comerciales, la Junta de Restablecimiento del Comercio. ${ }^{18}$

El estudio de esta junta de 1705, y su posterior evolución en la Junta General de Comercio en 1707, cuenta con una serie de obstáculos. El primero sería la pérdida parcial de la documentación generada por este organismo. ${ }^{19}$ De alguna manera esto puede explicar por qué la historiografía sólo ha trazado las líneas maestras de este tema. ${ }^{20} \mathrm{Y}$, en segundo lugar, que de la junta dependían innumerables asuntos que chocaban con las competencias de algunas secretarías y ministerios, como los de Marina, Guerra, Hacienda, Indias, etc.

Sobre la junta se ha discutido si tuvo su antecedente en la formada en tiempos de Carlos II en 1669, o si constituye una novedad, influenciada por los modelos institucionales franceses.

Siguiendo a Pérez-Mallaína podemos apreciar que los planteamientos franceses sobre el sistema de libre navegación, propuestos por Daubenton ${ }^{21}$ y Nicolás Mesnager, ${ }^{22}$ respondían más a sus intereses concretos en América que a un pensamiento más «liberal» — según el autor—, yo diría «aperturista». ${ }^{23}$ La obra de Jean de Monségur, fechada en torno a 1707-1709, más parece una descripción de las ventajas de la posible explotación del comercio colonial -específicamente del comercio con México epicentro del virreinato de la Nueva España-, por medio del establecimiento de una alianza hispano-francesa, que un verdadero proyecto de reformas. ${ }^{24}$

Las otras propuestas corresponden al plano del proyectismo de la época: navegación por medio de registros sueltos desde Cádiz; reforma drástica del sistema de flotas y galeones para hacerla más ágil; plan mejorado de defensa de los convoyes; el memorial de Bartolomé Antonio

17 El grado de influencia francesa en España ha sido analizado, entre otros autores, por PérezMallaína, 1982; Malamud, 1986; Lynch, 1993; Delgado Ribas, 2007, 74; y Desos, 2009. Referencias directas al asiento francés en Fernández Durán, 2011, 45-91.

18 Delgado Rivas, 2007, 77.

19 Sólo tenemos algunas pistas de su actuación por medio de algunos legajos del Archivo General de Simancas, que ahora no analizaremos, y de la obra de Larruga, 1788.

20 Molas Ribalta, 1978 y 1996,

21 Desos, 2005; Vázquez, 2013, 128.

22 Frey, 2005, 283-287. Véase Mesnager, 1990, 576-595.

23 Pérez-Mallaína, 1982.

24 Bély, 2013, 62-67. Véase la edición de las memorias de Monségur en Duriols, 2002. 
Garrote para agilizar las flotas y galeones ${ }^{25}$ y por último, la propuesta de Pérez Bustamante para la creación de una compañía de comercio, única alternativa con algo más fundamento frente a las propuestas francesas. ${ }^{26}$

Al final los acontecimientos bélicos interrumpieron todos estos proyectos, si bien cabe destacar el freno de la línea más «castizas» a las teorías francesas de libre navegación, que claramente perjudicaban los intereses españoles en América.

En la parte austriaca las intromisiones comerciales se multiplicaban. Son bien conocidos las negociaciones de las autoridades inglesas con Carlos III en Cataluña y el proyecto de formación de una compañía de comercio hispano-inglesa con las Indias fechado el 10 de julio de $1706 .{ }^{27}$ Pero el panorama fue mucho más complejo.

Las negociaciones con los ingleses lideradas por Antonio de Liechtenstein y Uhlefeld, primera figura de la camarilla palaciega de Carlos III, depararon un tratado de comercio nada desfavorable, y que incluía una rebaja de aranceles para los productos ingleses, además de potenciar el comercio de la compañía de comercio, con la concesión del arribo de diez embarcaciones inglesas al año a las costas de América. En 1709 se fundó la Companya Nova de Gibraltar, para establecer relaciones comerciales entre Gibraltar, plaza ya inglesa de facto a partir de 1704, con el puerto de Barcelona.

Pero no debemos olvidar las negociaciones de Felipe V y Carlos III a través de las Cortes catalanas en sus convocatorias de 1701-1702 y 1705-1706.

Las Cortes de Felipe V entre 1701 y 1702 intentaron poner en práctica las ideas de Feliú de la Penya, redactadas en 1683. En ellas se proponía la creación de una gran compañía de comercio de carácter mixto (privado y gubernativo), bajo la influencia de las compañías holandesas. El proyecto fracasó pero se concedió el envío de dos navíos a América.

Recordemos que en 1701 se proyectó en Barcelona la Compañía Náutica Mercantil, que surgió del interés catalán por participar en el comercio americano, por supuesto a través de la Carrera de Indias y bajo la fórmula de una compañía privilegiada por acciones. ${ }^{28}$ Este objetivo se va a ver

\footnotetext{
25 Delgado Rivas, 2007, 81.

26 Carrera Pujal, 1943-1947; Real Díaz, 1959; Hussey, 1962; Walker, 1979, 47; García Ruipérez, 1986.

27 Fernández Durán, 2001, 93.

28 Matilla Quiza, 1982, 304.
} 
como una reanudación de las inquietudes catalanas para la ampliación del radio de acción en los mercados ultramarinos. ${ }^{29}$

Las propuestas del comercio catalán van a ser aceptadas por el monarca pero se verán frenadas por dos hechos: la ambigua forma en la que se presentaban las propuestas; y el posterior desarrollo de la guerra, que les perjudicó considerablemente. ${ }^{30}$ En este sentido no es extraño que cuando se funde la Compañía de Barcelona entre 1755 y 1756, Cataluña tenga una dilatada experiencia en materia de comercio colonial.

Las Cortes de Carlos III entre 1705 y 1706 insistieron en las concesiones de comercio con América, con la aprobación del envío de cuatro navíos - el doble que en la anterior convocatoria—, y la formación de una especie de junta inter-estamental para la elaboración de un proyecto de compañía, la Compañía Náutica Mercantil y Universal.

Transversalmente, ya que estuvo presente en ambas convocatorias de Cortes, se planteó la creación de un puerto franco en Barcelona. Se convirtió en uno de los proyectos más importantes de la época, donde se concentraron todo tipo de intereses. Esta realidad atendía a las aspiraciones de la burguesía mercantil catalana.

La posibilidad de convertir a Barcelona en puerto franco fue planteada tanto en las Cortes de 1701-1702 como entre 1705 y 1706. La oposición a este proyecto venía de otras ciudades, por ejemplo Mataró y parte del patriciado de la propia ciudad de Barcelona, lógicamente no interesado en el comercio marítimo, y de algunos intereses particulares como los arrendatarios de derechos municipales o propietarios de la lezda real y de mediana.

En la práctica el proyecto no se realizó, ya que tras las primeras discusiones sobre el lugar del emplazamiento del puerto franco y la presión inglesa para aprobar el proyecto, en 1712 quedaba como algo inviable por las dificultades tanto internas como internacionales. Sin embargo, y desde el ámbito de los escritores políticos-económicos, podemos observar cómo algunos autores de los años 1724-1725 recuperan la necesidad de fundar un puerto franco en Barcelona.

Las Cortes de Aragón, al igual que las Cortes de Cataluña, fueron una ocasión para que se presentasen algunos proyectos de reforma económica.

29 Martínez Shaw, 1981, 142 y 254; Vilar, 1988; Rahola y Tremols, 1931. Estas inquietudes del comercio catalán estaban ya representadas en la obra de Feliú, a finales del siglo XVII, véase Feliú 1683, aunque no sólo para la concesión de la compañías sino para la creación de un puerto franco en Barcelona.

30 Vilar, 1992, 329-358. 
Principalmente se centró el interés en la formación de una gran compañía de comercio, bajo diferentes modalidades institucionales y la obtención de un puerto franco para Aragón en Vinaroz y Benicarló, además de potenciar la navegación fluvial por el Ebro. ${ }^{31}$ Una de las características del arbitrismo aragonés de finales del siglo XVII, apuntada por la historiografía, es su violenta francofobia, sobre todo por parte de los defensores de la producción artesanal. $^{32}$

\section{De Utrecht al gobierno Ripperdá (1713-1726)}

Los acontecimientos que hacen de esta etapa de la historia española un capítulo muy conflictivo son la reorganización administrativa de la Monarquía, los primeros años del reinado de Felipe $\mathrm{V}$, su abdicación en su hijo - Luis $\mathrm{I}_{-}^{33}$ y regreso al trono, que inaugura el segundo reinado de Felipe V, las repercusiones de la guerra de Sucesión, entre otros.

Estos años de incertidumbres trajeron consigo unos cambios constantes y, a veces, frenéticos en la gestión ministerial, que no propiciaron una política comercial continuada y bien planteada.

Es difícil intentar conjugar las actuaciones en materia de comercio y la defensa de ideas sobre política económica por los diversos altos representantes de la Monarquía española. Es patente durante estos primeros años del reinado de Felipe V la importancia femenina en los asuntos de gobierno, teniendo de un lado a la princesa de los Ursinos y del otro a Isabel de Farnesio. $^{34}$

31 En cuanto a las Cortes de Valencia de 1706, sólo cabe mencionar que lo que abunda en sus discusiones es la materia militar, con proyectos de creación de ejércitos, etc. Valencia no contó con un proyectismo sobre compañías privilegiadas de comercio. Sin embargo, se centró más en los privilegios y monopolios temporales de los artesanos especializados. Las Cortes de Mallorca, al igual que las de Valencia, no prestaron atención a las compañías, y sólo por medio de las discusiones de la Real Sociedad de Amigos del País conocemos algo de sus intereses comerciales. Las principales preocupaciones de los mayorquines se centraban de este modo en la agricultura.

32 Sobre el arbitrismo y proyectismo aragonés véase Sánchez Molledo, 1998 y 1999.

33 Para el reinado de Luis I nos tenemos que seguir remitiendo a las obras clásicas de Danvila, 1902 y 1952.

34 Pérez-Mallaína $(1982,359)$ expresa que «según la historiografía tradicional, el encumbramiento de Orry fue debido a la protección de la princesa de los Ursinos, que después de la muerte de la reina se ganó completamente la voluntad del monarca». Sobre Ursinos véase Frey, 1995, 453-455; Vázquez Gestal, 2013, 118-128, en especial nota bibliográfica 71. En la figura de Alberoni podemos ver la influencia de Isabel de Farnesio. Sobre Isabel de Farnesio véase Pérez Samper, 2003. 
La actuación de Antonio Cristóbal Ubilla y Medina, como secretario del Despacho Universal y del Consejo Real, la primera etapa de Grimaldo en Guerra y Hacienda, Mejorada en Justicia y Asuntos Eclesiásticos, etc., se mezclan con las decisiones de Orry, Tinajero y Macanaz, más señaladas que conocidas por la historiografía.

Se suceden numerosos acontecimientos que no otorgan ni estabilidad ni continuidad a este período: los cambios ministeriales de 1715, donde aparece como teórico sucesor de Ubilla la figura de Julio Alberoni; la continuación de Grimaldo en Estado; los repetidos cambios de titularidad en Hacienda, en un primer momento Giranda y luego José Rodrigo; la relación de Vadillo con la cartera de Indias, despacho que reparte sus funciones entre Marina, Guerra, Hacienda y Justicia; la presencia de extranjeros en la corte con Robinet y posteriormente Daubenton, todo ello formando un complejo entramado administrativo. ${ }^{35}$

No es por ello extraño el retraso de los negociadores españoles a Utrecht y el desconcierto en las negociaciones entre Francisco de Paula Téllez, duque de Osuna, el conde de Bergeick ${ }^{36}$ ministro de la Guerra, y el marqués de Monteleón, del Consejo de Indias ${ }^{37}$ La excepción a esta falta de unidad política está representada por el ministerio de Alberoni $(1715-1719) .^{38}$

A pesar de ello no fue hasta superar los tiempos del tratado de Utrecht cuando se escribió un capítulo interesante en la proyección de la historia marítima y comercial de España.

La unidad de las actuaciones se consolidó durante los primeros años de responsabilidad de José de Patiño, ya intendente general de Marina y presidente del Tribunal de la Contratación desde 1717. Desde esta fecha hasta su promoción a la Secretaría de Estado de Marina e Indias en 1726, dejó proyectos, remodelaciones, mejoras, etc., dentro de las responsabilidades de sus numerosos cargos.

La presencia política de Patiño no fue precozmente más efectiva por la decisión de Alberoni de abandonar la política de reformas para centrarse en las expediciones de Cerdeña y Sicilia; y, lógicamente, por los años del gobierno de Ripperdá.

35 Para el seguimiento de ministros y responsabilidades durante esta época véase principalmente Escudero, 1969 y Fayard, 1982.

36 Jan van Brouchoven (1644-1725), conde de Bergeyck (Bergeick en la documentación), véase Mur Raurell, 2011, 265, nota 1021; Frey, 1995, 42-43.

37 Fernández Durán, 2011, 119.

38 Taxonera, 1945a. 
Después del gobierno de Alberoni se mantiene la figura de José de Grimaldo en la Secretaría de Estado, ante la necesidad de consolidar el ministerio bajo una misma persona. A Daubenton, fallecido en 1723, le sigue el Padre Bermúdez, confesor del rey, con unas responsabilidades políticas destacadas, y que ya han sido señaladas por la historiografía. ${ }^{39}$

Durante 1723 se produce un interesante intercambio de correspondencia entre la Junta del Asiento, el representante de Felipe V en la compañía inglesa y diversos ministros de la época como Grimaldo y Ripperdá. ${ }^{40}$ Sin adentrarnos en el asunto que tratan - sobre la legitimidad del representante de Felipe $\mathrm{V}$ y unas concesiones dinerarias a algunos representantes ingleses de la compañía, presuntamente falsificadas-, el trasfondo es el verdadero galimatías para obtener información y el obsoleto e ineficaz sistema de representación y personación del rey Felipe $\mathrm{V}$ en los negocios de la compañía, ya que todo se tendría que consensuar en la Junta del Asiento, bajo la batuta de D. Andrés de Escobarrutia, mientras las reuniones en Londres seguían avanzando, lógicamente, sin esperar las respuestas de Madrid. ${ }^{41}$

Por estos años, estamos en 1724, se produce la abdicación de Felipe $\mathrm{V}$ en la figura del príncipe de Asturias, Luis I, ${ }^{42}$ lo que conlleva la organización de un nuevo gabinete, o tal vez más bien un cuerpo fantasma de gobierno, ya que la política siguió dirigida por Grimaldo.

Frente a la carencia de iniciativa del gobierno de Grimaldo se necesita un segundo Alberoni. Así, entre 1724 y 1726 se encumbrará la figura de Ripperdá como posible sucesor a este cargo. Sin embargo, y a pesar de la presencia de Castelar en Guerra, Patiño en Indias y Marina, y Grimaldo en Asuntos Exteriores, el gobierno de Ripperdá fue un fiasco y entró rápidamente en crisis. Una crisis motivada, según la historiografía tradicional, por la farsa de la abdicación, la meteórica ascensión de Ripperdá, la desorientación de la política española y la crisis de 1724-1726. ${ }^{43}$

39 Sobre Bermúdez véase Delgado Barrado, 2007, 229-230, y López Arandia, 2012. Su caída en desgracia por la presión de Isabel de Farnesio en Vázquez Gestal, 2013, 211-212.

40 AHN, Estado, lib. 835, 1114, Contiene algunos puntos sobre el asiento de negros de Inglaterra [1723].

41 Fernández Durán, 2011, 224, señaló que hasta 1730 no se supo cómo funcionaba realmente la compañía del asiento.

42 Danvila, 1902 y 1952.

43 Sobre la actuación de Ripperdá podemos consultar Vilar, 1985; Taxonera, 1945b; y Frey, 1995, 382-383. Mur Raurell, 2011, 265, exonera a Ripperdá de alta traición por falta de pruebas convincentes. 


\section{De los primeros escritos al punto álgido de la producción (1713-1726)}

La principal indagación de los escritores y sus escritos será reflexionar sobre la relación entre la presencia extranjera en España y las cotas de participación en el comercio colonial.

El periodo activo del asiento se mantuvo entre 1713 y 1718. El propio encargado de las negociaciones, en la junta para la negociación del tratado de Utrecht, Bernardo de Tinajero, había advertido a Felipe V de que el tráfico de negros sin la rentabilidad del contrabando de mercancías no era un negocio lucrativo. ${ }^{44}$ Tal vez fuese la creencia de que la participación de Felipe V en la compañía inglesa, fundada en 1711, repercutiría en beneficio de la financiación de la política dinástica.

Sin duda el peligro más evidente eran los lugares del establecimiento de factorías, nada más que en Veracruz, Portobello, Cartagena, Panamá, La Habana y Buenos Aires, ${ }^{45}$ desde donde los ingleses podrían controlar ferias y el comercio interno de los distintos territorios americanos.

Sin embargo, si parece que es cierto que durante estos años no tenemos constancia de escritos políticos-económicos de calado sobre estos temas, también pueda explicarse por las coyunturas políticas y comerciales del periodo: cambio de la cabeza del monopolio de Sevilla a Cádiz en 1717, la interrupción del comercio del asiento y permiso durante 1718-1721, la aprobación del Real Proyecto de Flotas y Galeones en 1720, las fases de posteriores ajustes de las reformas entre 1720 y 1723 y, por último, la nueva ratificación del asiento a los ingleses el 13 de junio de $1721 .^{46}$

Sin embargo, parece que estamos asistiendo a la antesala de lo que posteriormente vendría, la reorganización del comercio colonial a partir de 1726, aún más motivados e incentivados por los cambios de coyunturas políticas, fundamentalmente durante e inmediatamente después del gobierno Ripperdá entre 1724 y 1726.

Las ideas reformistas de Ripperdá tienen que superar el estado de meras conjeturas como la autovaloración de su propio reformismo - se veía a sí mismo como el gran reformador del estado-,${ }^{47}$ la descripción panegírica de sus allegados presentando sus ideas como «el más hermoso proyecto del mundo» — según el embajador imperial Königsegg—; o

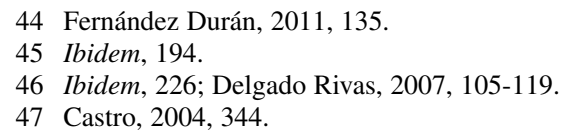


su relación estrecha con verdaderos estadistas y reformadores como Bergeick. ${ }^{48}$

Pero precisamente el punto álgido en la producción de literatura política y económica sobre asiento y navío está centrado entre los años 17241726, y que Delgado Rivas ha precisado en una coyuntura más dilatada en la parte final abarcando $1725-1728,{ }^{49}$ por la inclusión de las juntas presididas por José Patiño entre 1726 y 1728.

El silencio de Gerónimo de Uztáriz en Teórica y práctica de comercio y marina de $1724^{50}$ sobre el asiento de negros, más interesado por el comercio ilícito, principalmente en el cometido en el Seno Mexicano, se debe a la intencionalidad de la obra y sus características formales, es decir, por compilación de muchos materiales misceláneos realizados por escritores extranjeros.

Sin embargo, no podemos olvidar la experiencia de oficiales del otro lado del Atlántico, cuyos representados fueron los principales afectados por las concesiones comerciales a extranjeros.

En este sentido la publicación de la obra de Gerardo Moro de 1724 no es gratuita ni espontánea. Moro fue miembro de la Real Audiencia de México ${ }^{51}$ y realizó un estudio jurídico y legal del asiento, sobre todo para demostrar los daños en alcabalas y por las internaciones de mercancías, ${ }^{52}$ que repercutían negativamente en los beneficios de los arrendadores de rentas reales y de los asentistas indianos. ${ }^{53}$ Este era una denuncia de daños específicos en territorios concretos sobre las basas del comercio colonial motivados por la concesión del asiento a la compañía inglesa.

Por otro lado, Dionisio de Alsedo y Herrera - por entonces diputado general del comercio de Lima- ya desde 1724, si no con anterioridad, denunciaba por escrito las nefastas consecuencias de la concesión del asiento a los ingleses. La solución del mal, los abusos de las factorías, pasaba por el control del arqueo a través de una junta particular. ${ }^{54}$

A partir de 1725 se desatan las críticas hacia la posesión inglesa del asiento de negros. La mayoría son obras anónimas, es decir, que descono-

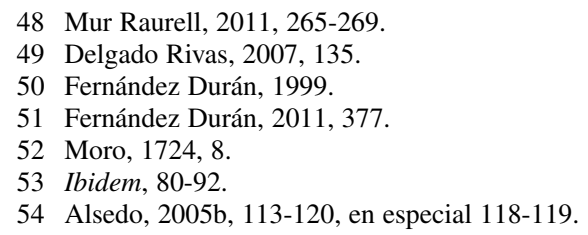


cemos por diversos motivos el nombre de sus autores, aunque de algunos de ellos tengamos ligeras pistas biográficas.

Por ejemplo, sí conocemos las ideas expresadas por Varas Valdés a partir de 1725, aunque el autor forme parte de los ministros de Felipe V y de que sus escritos tengan una intencionalidad clara de confirmar la política de sus superiores.

Si bien no será hasta el gobierno de Patiño, y más específicamente a partir de 1730-1732, cuando se indague desde la cúspide del poder los resultados de la concesión del asiento a los ingleses, ${ }^{55}$ tenemos algunas referencias cronológicas que nos retrotraen al año 1725.

Según parece desprenderse por la documentación consultada, el ministro Juan Bautista Orendain ${ }^{56}$ encargó a Varas Valdés, futuro presidente de la Casa de la Contratación hasta 1739, un informe o memorial para que estableciese el mejor método para rescindir el contrato del asiento en posesión de la compañía inglesa. ${ }^{57}$ Ya en 1732, con el nombramiento de Tomás Giraldino como director por España de la compañía inglesa, se estaba procediendo a aclarar el galimatías de sus cuentas y beneficios.

Varas y Valdés había redactado una primera memoria, y tal vez no por encargo de sus superiores, donde señalaba los principales males del asiento y la necesidad de rescindir el contrato:

tengo muy presente cuanto expuse a S. M. en mi representación de 28 de febrero de este año (1725) en estos asuntos y entre sus diversas cláusulas fue el que fenecido el actual asunto no se pensase el ejecutar otro con nación alguna extranjera, por consistir en estos negocios la total ruina y perdición de la América. ${ }^{58}$

Además, según el autor, era recomendable no hacer coincidir el arribo del asiento con el periodo de ferias en Portobelo y Veracruz. ${ }^{59}$

Pues bien, en torno a esta visión crítica del asiento de negros tenemos que añadir otros escritores y escritos: la Representación universal de 1725 , la Representación hecha a S.M. de 1725, los Discursos anónimos de 1725 y un Manifiesto, fechado en torno a 1726.

55 Delgado Rivas, 2007, 137-138.

56 Sobre Orendain véase Mur Raurell, 2011, 24-30 y 40-44.

57 El Memorial de Varas Valdés en cuanto a la defensa de flotas, galeones y registros anuales, ha sido reseñado por Delgado Rivas, 2007, 145,

58 Fernández Durán, 2011, 224.

59 Ibidem, 254. 
La Representación universal de $1725^{60}$ será uno de los primeros textos que analice con una mayor profundidad los males de la presencia extranjera en España, la connivencia entre éstos y españoles frente al contrabando, el poder manufacturero, el daño de piratas y corsarios, la presencia de colonias extranjeras en América y, sobre todo, de la concesión del asiento de negros a Inglaterra.

Parece desprenderse por el texto que se trata de dos escritores extranjeros, elemento ya apuntado por Manuel Colmeiro:

Forma este manuscrito un grueso volumen de autor desconocido, aunque el contexto deja entrever que son dos y extranjeros de origen, si bien antiguos vasallos del Rey de España. Tocan infinitas materias y cuestiones relativas al gobierno político y económico de la Monarquía, y por más que se muestren apasionados en demasía al sistema prohibitivo, no dejan en otras partes de proponer útiles reformas y dar sanos consejos a Felipe V. ${ }^{61}$

Efectivamente, y a lo largo del prólogo, podemos localizar algunas pistas de sus autores:

Si haya habido algunos que han proyectado algún remedio a tantos males y V. M. remitido el proyecto a algunos ministros le han atacado como arbitrista de novedades, reformador de abusos y pescador de conveniencias, bajo el pretexto del servicio de V. M. y basta que no sea natural de España, aunque vasallo experimentado de V. M., para no darle ni un crédito.

Y más adelante, «...porque somos dos pobres, aunque fieles y honrados, vasallos de V.M.».

En cuanto a la fecha de redacción podríamos apuntar la hipótesis de los años $1722-1723,{ }^{62}$ ya que:

Discurridas pues a fondo las causas de tantos deplorables daños que padece V. M. y su Monarquía nos hemos aplicado por el espacio de casi de cuatro años a ver su

60 Biblioteca Nacional de España (BNE), Ms. J. 69, Representación universal del estado de la Real hacienda, gobierno, económico, comercio y marina de las Indias; de los desórdenes, daños e inconvenientes que al presente hay, con sus remedios y con la forma fácil de su mayor y respectivo adelantamiento para la mayor gloria de S.M. Alivio de sus vasallos y exaltación de la Monarquía de España, Madrid, 28 de julio de 1725.

61 Colmeiro, s.f., 34, registro 79; Correa Calderón, 1981, 186 registro 1366 y 188 registro 1389; y la reseña de Elorza, 1970.

62 En este tipo de escritos caracterizados por el desconocimiento del autor o autores y además, en algunos casos, que no son fuentes originales sino copias, es muy importante diferenciar entre la fecha o fechas de redacción y la fecha de publicación, envío o recepción. Delgado Barrado, 2007, 51-71. 
origen, leído todas las leyes, tomado infinitos informes y tenido varias noticias de hombres de crédito y de verdad y experiencia.

Sobre el asiento de negros opina que por la escasez de fuerzas marítimas no se puede romper este sistema, y del que habría que desentenderse prudentemente hasta mejores tiempos. El verdadero problema estaba en el contrabando que realizaban los factores del asiento y de algunos de sus directores. El asiento era capaz de destruir por sí solo todo el comercio de las flotas y galeones, por adelantarse a la ferias novohispanas y competir en precio y calidad, es decir, romper el monopolio español y utilizar el chantaje comercial como moneda de cambio. Algunos de estos pensamientos y reflexiones podríamos compararlos con los expresados por Varas y Valdés.

La Representación hecha a S.M., fechada en Madrid el 28 de julio de $1725,{ }^{63}$ precisó que algunas condiciones del asiento de negros firmado con los ingleses son aprovechadas para introducir contrabandos abusivos, especialmente por las actuaciones de los factores de la compañía a sabiendas de los ministros españoles. El autor se fundamenta en «experiencias que he adquirido en los puertos y costas de la América». ${ }^{64}$

Los Discursos anónimos fechados el 24 de abril de 1725 están firmados por un tal Sr. D. J. C., por ahora de autor desconocido. ${ }^{65}$ En el mismo título se resume la principal aportación:

la permisión concedida a la Compañía de Inglaterra, que debiendo enviar anualmente un navío delimitado a Veracruz, otro a Cartagena y otro a Buenos Aires, cargaban tanto como una mediana flota de galeones y anticipándose a los que salía de estos reinos o no encontraban éstos venta o se veían precisados a hacerlas con descalabro y pérdida. ${ }^{66}$

El escrito Manifiesto, redactado presumiblemente en 1726, también señala como uno de los principales estorbos del comercio el asiento de

63 BPR, II-2839-B, 283r-309v, Representación hecha a Su Majestad el año de 1725 sobre los perjuicios que se seguían al erario y comercios de España e Indias de algunas de las condiciones del asiento de negros ajustado con la Inglaterra el de 1713; y abusos en la práctica de otras, por la contravención de los factores y tolerancia de los ministros reales, en no impedir el contrabando que a la sombra del asiento se ejecutaba. Citado por Fernández Durán, 2011, 248.

64 Ibidem, 292.

65 BPR, II-2863-B, 1-18, Discursos anónimos sobre el abatimiento en que se hallaba el comercio de España con sus Indias en el año de 1725 por la libertad y desahogo con que lo hacías los franceses en el Mar del Sur, provincia de Caracas e islas de Barlovento; y por la permisión concedida a la Compañía de Inglaterra, Madrid, 24 de abril de 1725.

66 En el texto citado la Compañía de Inglaterra era también denominada como Compañía Real de Inglaterra. 
negros y el navío de permiso, aunque no se detiene con detalle sobre este punto:

El asiento de negros con ingleses y el navío anual del permiso es el mayor estorbo que hoy tenemos para ver el buen corriente que deseamos el comercio de la América, pero haciéndome cargo que V.E. se hallará instruido de la mala fe con que ha procedido la Compañía y de los muchos y continuados excesos que se están cometiendo con sus navíos y por sus factores, no me detendré en hacer expresión de ellos, en inteligencia de que siempre que se ofrezca lo ejecutaré en la mayor individualidad. ${ }^{67}$

Desconocemos quién fue el autor, aunque tuvo que ser miembro del Consulado del Mar, y cita numerosos documentos oficiales (real proyecto de 1720, real cédula del 22 de octubre de 1724, cartas, etc.), y está al tanto de las salidas y llegadas de flotas, como la salida de flotas del 15 de julio de 1725 .

El autor del Manifiesto ofrecía tratar el tema con mayor detenimiento, si así se le indicaba. Además, no era la primera vez que había expuesto sus ideas, ya que reconoce que había presentado anteriores escritos, en concreto «una reverente representación a S.M.».

Lo importante es que a la altura de 1726 el daño del asiento y navío para los intereses españoles estaba más que identificado, que la Corona era buena conocedora de tamaña intromisión en el comercio colonial y que existía una profusa literatura. ${ }^{68}$

\section{Del gobierno de José Patiño en 1726 a la crisis de 1739 $y$ el fin de los «gobiernos vertiginosos» en 1741}

A partir de 1726 era la hora de las reformas y negociaciones. A partir de 1727 era la hora de Isabel de Farnesio. ${ }^{69}$ Desde el punto de vista político presenciamos una doble característica: en un primer momento un fortalecimiento político de la monarquía; y en segundo lugar una primera

67 BPR, II-2863-B, 94-106, Manifiesto que hizo al ministerio de las Indias un sujeto versado en materias de comercio. También aparece como Fraudes.

68 Alsedo y Herrera (2005b, 149) hacía referencia a que la Junta de 1726 había demostrado el daño casi irreparable al comercio por la concesión a los ingleses en 1714 del asiento, navío y la cesión de la Colonia de Sacramento.

69 Vázquez Gestal, 2013, 224, señala que a partir de 1727 la reina despachaba ya como gobernadora en los periodos de enfermedad del rey, que cada vez eran más frecuentes, que sólo confirmaba una realidad ya puesta con anterioridad en práctica. 
estabilización de los anteriores resultados y una segunda de decaimiento político que nos lleva a los resultados de la crisis de 1739 .

La primera fase comprenderían los años 1726-1736, que corresponden a la presencia de José Patiño en sus cargos ministeriales; una segunda fase entre 1736 y 1741, de mayor crisis ministerial con los gobiernos de la Cuadra, Torrenueva, Iturralde y José Quintana, y la crisis de 1739, que marca un antes y después del reformismo borbónico.

Desde la óptica comercial tenemos dos claras etapas entre los años 1726-1733 y 1733-1740. En ambas alternan períodos de reflexión política y práctica ministerial, no ajenos a dificultades de acotaciones cronológicas. Tanto en el marco político como en el comercial frente a unos años de esplendor renacen otros de crisis.

Desde la óptica política no es una casualidad que los años de esplendor correspondan a la actuación de Patiño (1726-1736), ${ }^{70}$ y los segundos al periodo de gobierno desde La Cuadra a Quintana (1737-1740), más desatendidos por la historiografía.

Sin embargo, los elementos dinamizadores de la crisis de 1739 debemos verlos en germen en el propio gobierno de Patiño. Por lo tanto, es fundamental la actuación de Patiño tanto política como comercial para entender los posteriores acontecimientos desde 1736 a 1741.

Bajo la figura de Patiño se reúnen bajo una misma mano los ministerios de marina e Indias (1726), Hacienda (1726), Guerra (1730) y Estado (1734). Como vemos la figura de Patiño actúa de forma personalista en los mecanismos de la Monarquía. Patiño prestó especial interés por el comercio americano, y centró parte de su política a resolver los problemas del tráfico comercial, presencia extranjera en las colonias, etc. La Junta de Comercio fue un mecanismo de actuación utilizado por anteriores gobernantes pero con él fue una herramienta de trabajo, de foro de discusión y de toma de decisiones.

Aunque los años 1726-1745 representan una nueva etapa para la vida de la Junta de Comercio con la presencia de Gerónimo de Uztáriz (1729) y el enfrentamiento con el Consejo de Castilla, hubo un mayor interés a partir de 1730 por los temas hacendísticos de la economía peninsular relacionados con el comercio de Indias: nuevo sistema de recaudación de los

70 Sobre José Patiño véase Rodríguez Villa, 1882, Mclachlan, 1940, 146-152 y Bethencourt Massieu, 1954, junto a los de Walker, 1979; Ruiz Rivera, 1985, 16-21; y Lynch, 1991, 83-89; y los más recientes de Crespo Solana, 1996 y Delgado Rivas, 2007, 135-140. 
impuestos arancelarios, medidas para terminar con el fraude y las prácticas ilegales, aumento del valor de la moneda, etc. ${ }^{71}$

Por lo pronto asistimos entre 1726 y 1728 a un pequeño intento de dañar los privilegios andaluces en la Carrera de Indias - y por ende de los intereses comerciales extranjeros- y a un reajuste y replanteamiento del comercio con América, todo dentro del respeto del sistema de flotas y galeones. ${ }^{72}$

Las constantes en la política de Patiño serán la lucha contra el navío de permiso, la reglamentación del sistema de flotas y galeones, el apoyo a las compañías privilegiadas, etc.

Las propuestas de frenar los contrabandos de los extranjeros - fundamentalmente del navío de permiso-, fueron glosadas por Alsedo y Herrera como resultado de las conclusiones de las Juntas de 1726, 1727 y 1728 :

se hacía preciso como único y conveniente medio eficaz para atajar estos daños comunes y evitar los designios de hacer conquistas y en ampliar sus comercios, quitar la prohibición de ser privativa de los españoles la navegación a los mares y costas de los dominios de Su Majestad, haciéndola libre generalmente a todos los navíos y francos los puertos extraviados de las carreras de Flotas y Galeones. ${ }^{73}$

Y más adelante precisó el método:

navegaría cada reino sus propios géneros y mercaderías repartiéndose distributivamente entre todos la utilidad de los comercios..., que ninguno pensaría en serlo ni hacer conquistas porque era una Compañía Real de comercios, dependiente de una liga política de intereses en que todos los demás habían de ser enemigos confederados contra el que lo intentase..., porque todos serían celadores de que ninguno abusase de la libertad del tráfico en perjuicio de los demás y harían que se le expeliese del permiso de la navegación. ${ }^{74}$

Y todo ello a la altura de 1728: libertad de comercio con América, en los términos expresados en el escrito, formación de una Compañía Real de todas las provincias y puertos interesados en el comercio colonial, neutralización del contrabando... Los tiempos demostraron que sus ideas, adelan-

71 Valoración realizada por Molas Ribalta, 1975, 795-802, que refuerza la idea expresada por Walker, 1979, 203, sobre el considerable aumento del interés prestado por José Patiño a la Real Hacienda frente a otros gobiernos.

72 Delgado Rivas, 2007, 131.

73 Alsedo, 2005b, 362.

74 Idem. 
tadas a su época, todavía no tendrían cabida entre las dimensiones reales de los intereses cruzados de los beneficiarios finales del comercio colonial.

Entre las ideas hacendísticas de Patiño continúa la persecución y freno al contrabando, reformas monetarias y nuevos métodos de recaudación. En la práctica, y como hemos visto, fueron dos temas principalmente los que más se repiten: la reorganización del sistema comercial con América y las compañías privilegiadas. Todos estos procesos de cambio, o intentos de cambios, del sistema comercial con América y de la vida política y económica de la Monarquía culminaron en 1739.

En ese año se acumulan las diferencias entre España e Inglaterra dando paso a la guerra, se produce una crisis hacendística de gran magnitud, se comprueba el fracaso de la política comercial con América de los últimos años, principalmente con el revés de la flota de 1735 y los galeones de 1737, etc. A esto se debe unir el aumento del gasto de la Monarquía; por otro lado la muerte de Patiño en 1736 y la suerte de ministros que ocupan sus nuevos cargos.

La Junta de Medios entre 1737 y 1740 tuvo un papel significativo en la acción de gobierno de la Monarquía Hispánica. Tras el estudio de Albadalejo, ${ }^{75}$ basado en la consulta documental del Archivo General de Simancas, parece evidente que el sistema financiero de la Monarquía hizo aguas en 1739. La explicación puede estar en la política interior y exterior de la monarquía durante estos años. En política interior pudieron ser elementos generadores de la crisis los gastos de la Casa Real en Italia, las construcciones reales y la política de actuación de Patiño. En el caso de la política exterior los sitios de Gibraltar (1726-1727), la expedición a Italia (1733-1735), la conquista de Orán (1732), la eminente guerra con Inglaterra (1739), etc.

La creación de la Junta de Medios, con el papel protagonista del secretario Alejandro de la Vega, así como de los asuntos tratados y conclusiones realizadas, puede seguirse a través de los documentos localizados en el Archivo Histórico Nacional. ${ }^{76}$ Más adelante veremos el papel de la Junta de Medios como receptora de memorias e informes de toda índole para la reforma de España.

En definitiva, finaliza un período donde se hacía cada vez más difícil el comercio con América por la complejidad de los intereses gaditanos,

75 Fernández Albadalejo, 1977, 51-85.

76 Delgado Barrado, 2009, 395-408. 
mexicanos y peruanos, y por la presencia inglesa en América, por medio del asiento de negros y navío de permiso, entre otros aspectos. Si a esto añadimos una política todavía pendiente de compromisos dinásticos podemos ver como Patiño se convierte en un prisionero de la Corona, reducido a cumplir su misión, que no era otra que la de conseguir los recursos necesarios para la guerra. ${ }^{77}$

\section{La política comercial entre 1726 y 1739}

Como hemos dicho los principales problemas que se intentan resolver son lo relacionados con el buen funcionamiento del comercio con América. Para ello se va a intentar poner en práctica dos medidas: la mejora del sistema tradicional de navegación, las flotas y galeones, y la utilización y apoyo a las compañías privilegiadas. ${ }^{78}$ En ambos casos los resultados están más llenos de proyectos frustrados que de un buen funcionamiento de los mismos.

Las reformas del sistema de navegación con América constituyen unos de los temas clave del interés político de la Monarquía. El inicio a partir de 1726 de una nueva actitud frente a los problemas se debe a la clara influencia de las etapas del comercio colonial en años pasados que predisponen a una necesaria actuación en esta materia.

En torno a 1726-1728 asistimos a uno de los acontecimientos más importantes del comercio colonial, ya que se produce un intento por reajustar o replantear el comercio con Indias. ${ }^{79} \mathrm{~A}$ decir de algunos autores asistimos a la primera parte de un estudio a gran escala del comercio con América desde la propia Corona, que posteriormente será recogido por otros monarcas y ministros en sus planes de reforma.

Bien es cierto que no hubo una reorganización del sistema comercial, aunque se intentó mejorar el sistema de galeones vía Buenos Aires, introducir la Compañía de Ostende, etc. Pero si se realizaron unas nuevas reglamentaciones para el comercio con Filipinas, que afectaba a los intereses

77 Esta idea de «prisioneros de la Corona» para referirse a la actuación política tanto de Patiño, Carvajal y Ensenada es de Lynch, 1991, 90.

78 Como la creación de la Compañía Guipuzcoana de Caracas el 25 de septiembre de 1728, Delgado Rivas, 2007, 136.

79 Estas reuniones para el intento de reajustar el comercio colonial están estudiadas por Walker, 1979, 207; y Mariluz Urquijo, 1982, 62-63. 
gaditanos, y la institucionalización del sistema de ferias comerciales para Nueva España (2 de abril de 1728).

Toda política que significara algo más que estos tímidos reajustes ponía en peligro el propio comercio americano, que quedaba sometido una y otra vez a la presión extranjera, concretamente con el navío de permiso inglés.

La polémica sobre el asiento de negros y navío de permiso durante estas fechas no debía ser vana cuando provocó de manera indirecta dos guerras, primero la de 1727-1728 y posteriormente la de 1739. Además se intentó acabar con este privilegio por vías legales y acuerdos diplomáticos. A partir de 1731, bajo los influjos del Tratado de Viena, se destapó la verdadera dimensión del problema del asiento y navío.

Los juegos de intereses eran múltiples, variados y, en algunos casos, en apariencia incongruentes. Para entender el todo debemos diseccionar los variados frentes de intereses: la Corona británica, la Corona española, los accionistas de la Compañía inglesa, el Gobierno inglés, el Gobierno español..., dejando de lado a los sufridores de estos mecanismos, los comerciantes del comercio colonial entre España y América.

En el Tratado de Viena de 1731 se consolidó una posición que demandaba un mayor control español en las gestiones del asiento de negros y navío de permiso. Como señaló Reyes ${ }^{80}$ los comerciantes y accionistas de la compañía inglesa, vieron inviable el comercio de negros y solicitaron una compensación para suspender el tráfico. El gobierno británico se negó rotundamente. En 1732 los comerciantes de Cádiz ofrecieron pagar el dos por ciento del dividendo anual de los beneficios de las flotas y galeones como compensación a la compañía ${ }^{81}$ Durante 1732 Tomás Giraldino intentó aclarar las maniobras del asiento, dentro de una política de mayor control, ejercida por Orendain y Patiño, cuyo resultado, como hemos visto, fue el informe de Varas Valdés a Felipe V, quien señaló los perjuicios del asiento para el comercio colonial, y propuso que nunca coincidiera el arribo de los navíos con las ferias de Portobelo y Veracruz. ${ }^{82}$

En 1735 hubo nuevas negociaciones, esta vez por vía diplomática, y que descubren los verdaderos intereses de cada una de las partes. Es fundamental entender las diferentes ventajas entre el asiento y el navío, aunque sean elementos conjuntos e inseparables. Los accionistas del asiento quisieron la negociación con España, ya que el negocio como tal no era renta-

80 Fernández Durán, 2011, 228.

81 Ibidem, 262.

82 Ibidem, 224, 254 y 259. Véase Delgado Rivas, 2007, 139. 
ble. Felipe V, como accionista, también, ya que los perjuicios eran considerables, principalmente desembolsar grandes cantidades a cambio de no recibir compensaciones. El gobierno inglés siempre estuvo dispuesto a negociar la cesión del navío - los gastos de fletes, el intercambio más controlado, las limitaciones de carga, etc., lo hicieron poco efectivo-, pero no así del asiento, ya que por medio de la compañía pagaban los sueldos de embajadores y otros oficiales reales, sin tener que tirar de la caja de la Real Hacienda. ${ }^{83}$

Resumiendo, si el trienio 1726-1728 podemos definirlo como de preparación teórica del sistema de navegación, en el quinquenio 1729-1733 asistimos al funcionamiento práctico de las flotas y galeones. La flota de 1729 fue un total éxito, que lamentablemente no se repetiría en años sucesivos. Los galeones de 1731 y la flota de 1733 cierran una etapa de fracasos continuos por diversos motivos: presencia del navío de permiso, resistencia de los comerciantes en el denominado «chantaje comercial», saturación de mercados, etc.

Frente a este fracaso se actuó principalmente por dos vías: la reforma legislativa y la formulación de compañías privilegiadas. En 1734 se reúne una comisión de expertos para intentar solucionar los males del comercio con América. ${ }^{84}$ Tras las consultas se promulgó la real cédula del 21 de enero de 1735 sobre el despacho de galeones y flotas, y el método de comerciar los residentes en Indias con España.

De forma general sus principales características eran la suspensión temporal de las flotas, nueva reglamentación para la Armada del Sur y el sistema de avisos, reducción del quinto real, la prohibición a los comerciantes de América de enviar dinero a España —que sólo inició un proceso legislativo en aumento en torno a este problema-, y un reajuste del sistema de flotas con restricción del tonelaje (tres toneladas en siete u ocho navíos) y de carga (dos toneladas de mercancías generales y una tonelada de productos agrícolas, respetando el tercio de cosecheros). De este modo se perdían las ventajas obtenidas por el real proyecto de 1720. Sin embargo el sistema de flotas y galeones estaba tocado. Ni la flota de $1735 \mathrm{ni}$ los galeones de 1737 tuvieron éxito. Cada vez era más difícil comerciar con este sistema. La futura situación de guerra con Inglaterra iba a motivar el cambio de las flotas y galeones por los registros sueltos.

83 Fernández Durán, 2011, 261 y 277.

84 Walker, 1979, 242. 


\section{Pocas reflexiones, muchas reformas y grandes esperanzas}

Deberíamos reconsiderar la hipótesis de que existieron pocos escritores político-económicos entre 1726 y 1741 que tratasen los temas del asiento de negros y navío de permiso. No es tanto por el hecho en sí de que sí hubo durante éste periodo escritores políticos-económicos que hicieron referencia directa o indirecta a estos asuntos, sino por la necesidad de consultar más fondos documentales, principalmente de las tres juntas de especial importancia para estos temas: la Junta de Expertos de Patiño de 1734, la Junta de Medios entre 1737 y 1740 y la Junta del Asiento, apenas explorada siendo las más longeva.

Las dos primeras juntas fueron mecanismos de gobierno receptores de proyectos de reforma. Entre sus responsabilidades estaban el control de la presencia extranjera en el comercio colonial y, específicamente, del asiento de negros y navío de permiso concedido a los ingleses. En todo caso, otra de las posibles explicaciones del vacío documental estaría relacionada con el cambio del paso de la reflexión intelectual a la acción de Estado entre 1726 y 1741 .

Nos fijaremos brevemente en la Junta de Medios entre 1737 y 1740, como un ejemplo metodológico que podríamos aplicar a las otras juntas si tuviéramos información, tiempo y espacio.

El papel de la Junta de Medios como receptora y generadora de escritos relacionados con los males de España y sus posibles soluciones ha quedado recientemente comprobado ${ }^{85}$ En este caso nuestra atención recaerá en la presencia o ausencia de los contenidos sobre asiento y permiso concedidos a los ingleses.

El secretario de la Junta de Medios, Alejandro de la Vega, ${ }^{86}$ fue un ministro atento a los asuntos hacendísticos y, como no podía ser de otra manera, prestó atención al asiento de negros. Para ello recopiló los documentos fundamentales para la interpretación del asiento, como la copia impresa de la real cédula fechada en Madrid el 7 de abril de 1713, elaborada por Bernardo Tinajero, y la cédula de la declaración de algunos artículos fechada en el Buen Retiro de Madrid el 12 de junio de 1716, elaborada por José de Grimaldo. ${ }^{87}$

85 Delgado Barrado, 2007, 86-110; para una visión desde la Real Hacienda, Delgado Barrado, 2009, 395-408.

86 Delgado Barrado, 2009, 395-396.

87 Los documentos citados están localizados en AHN, Estado, lib. 786, documento 3 y 4. 
Esta recopilación documental impresa va seguida de un amplio resumen manuscrito, incluidas las notas de los documentos originales, realizada por Alejandro de la Vega, a las que añade unas Reflexiones sobre los perjuicios del asiento de negros. ${ }^{88}$

Las reflexiones de Alejandro de la Vega atienden a responder de los perjuicios que el asiento ocasionaba a los reinos. Según Vega las opciones en 1713 eran continuar la guerra contra los ingleses o concederles el asiento aunque supusiera la ruina del reino. Sin embargo, planea sobre estos acontecimientos la política de Estado, es decir, lo que «el vulgo ignora [de] los interiores de los gabinetes y las razones que hay para ceder en varios casos [y] fácilmente juzga lo que no sabe».

Sin embargo, Vega señaló que tanto para los ministros españoles como franceses sería conveniente «cortar incendio que no sólo [... llevaría] a la ruina del todo sino también [... afectaría] al honor y conservación de ambos reinos». Por medio del asiento los ingleses realmente tenían controlado el comercio universal en las Indias dañando los intereses del comercio gaditano. Anota Vega que si el navío de permiso se limitase a cumplir las leyes y acuerdos sería un daño menor, pero en la realidad introducía víveres y otras mercancías desde Jamaica, con lo que convertía en inútil el comercio español y propiciaba la decadencia de las fábricas.

Finalizaba señalando la importancia y gravedad del asunto:

Siendo como es este punto el de más vigor que pide y merece la mayor reflexión, considerándole no sólo digno sino el más excepcional de los negocios de Hacienda, he querido hacer esta sucinta expresión y a fin de que haya una noticia segura de las condiciones del asiento, y el menos trascendente conozca los daños incluso las condiciones de él, léanse con atención y nótese su gravedad.

La proximidad del final del asiento en el año 1743, más la gravedad de las finanzas entre 1737 y 1740 , explican estas reflexiones y advertencias de Alejandro de la Vega.

Entre la documentación de la Junta de Medios también localizamos otro memorial titulado Sobre los perjuicios ${ }^{89}$ que presenta un glosa crítica de los típicos males del asiento por el contrabando y la introducción de todo tipo de mercancías, la aniquilación de las ferias, así como de la perju-

88 Ibidem, documento 5.

89 AHN, Estado, lib. 779, documento 5. 
dicial información que lograban adquirir los ingleses del sistema del comercio colonial español. El remedio propuesto era extinguir los derechos del asiento y castigar a los ministros que permitían los ilícitos comercios, siendo responsables de ejecutar estas medidas el consulado y comercio de Andalucía.

Para Bernardo de Ulloa los principales males del comercio venían motivados por el asiento de negros concedido a los ingleses, ${ }^{90}$ por el poder que ejercen las colonias extranjeras dentro del comercio colonial español, la actuación de la piratería y del ilícito comercio, el corso de los moros de Berbería, ${ }^{91}$ etc.

Concretamente sobre el asiento de negros llega a decir que era el principal obstáculo del comercio:

[se opone] a nuestro tráfico marítimo el asiento de negros celebrado entre la Corona de España y la Gran Bretaña, y su daño se extiende al comercio español con la América, pues, además de los crudos permitidos para el vestuario, se valen de otras negociaciones ilícitas los ingleses para surtir aquellos reinos de todas mer-

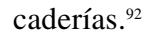

Denunciaba Ulloa cómo el poder extranjero era cada día más fuerte por las conquistas o los terrenos usurpados por los extranjeros, principalmente en las Antillas, en Jamaica y Curaçao. ${ }^{93}$

El material acumulado por Dionisio Alsedo y Herrera desde 1727, cuando José Patiño le encargó redactar un memorial sobre dos temas candentes del comercio colonial como eran el asiento y navío, culminó con la publicación del Aviso histórico en 1740. La propuesta de Alsedo fue la formación de una gran armada para controlar el dominio del mar y así del comercio. ${ }^{94}$ La solución de Alsedo era inviable en plena guerra contra Inglaterra, después de la bancarrota de 1739 y sabiendo perfectamente que

90 Anes, 1992; ideas ya estudiadas por Bitar Letayf, 1968, 97-109. Sobre las ideas relacionadas con el asiento, véase Fernández Durán, 2011, 377. Su perfil en Fernández Durán, 2007a, 66; y más reciente en González Limón, 2013, 227-242.

91 Sobre este punto había reflexionado Moya y Torres entre 1727 y 1730 (Moya Torres, 1992). Un reciente perfil biográfico y análisis de este escritor en Delgado Barrado, 2013, 183-193.

92 Bernardo de Ulloa, 1740, 139.

93 Si comparamos el escrito de Bernardo de Ulloa con la Representación de 1725 vemos como existe un paralelismo bien sea motivado por el conocimiento del primero de esta obra o bien porque los males se repetían a lo largo de los años.

94 Véase Alsedo, 2005a; Alsedo, 2005b, 169-171. 
el asiento mantendría su vigor hasta por lo menos $1743 .{ }^{95}$ A tiempos desesperados medidas desesperadas.

Y, por último, Marcelo Dantini, cuya obra Diálogos familiares..., presumiblemente redactada en 1741, fue uno de los autores que más detalladamente trató los contenidos relacionados con la presencia en España de comerciantes extranjeros. Dedicó unas líneas para reflexionar sobre la diferencias entre el contrabando y el comercio directo. El comercio directo era el realizado por los extranjeros desde sus puertos nacionales «directamente» a la América española. ${ }^{96}$

Malamud señaló acertadamente que el comercio directo:

será utilizado exclusivamente para aludir a toda la actividad comercial, en cualquiera de sus variantes, realizada por los europeos no españoles con las posesiones americanas de la corona hispana, y sin la intermediación andaluza. ${ }^{97}$

Para Dantini el asiento de negros era uno de los principales medios de fraudes a la Real Hacienda, ${ }^{98}$ y que será profusamente tratado a lo largo de su obra. ${ }^{99}$ El valor de esta permisión fue la concesión de una vía legal, en primer lugar para los franceses ${ }^{100}$ y más tarde para lo ingleses, para llegar a la América hispánica. El resto era cuestión de habilidad para introducir los géneros prohibidos en los mercados coloniales. Para ello se valían de la entrega de comisiones a los jefes de los puertos, del envío de avisos de las necesidades concretas de determinadas zonas de la América, etc.

Las soluciones propuestas por Dantini no iban más allá de la elección de buenos jefes de puertos, la política del premio y castigo, el control de los oficiales y la elección de un buen ministro. El exigir soluciones concretas a un problema tan complicado, como los problemas del contrabando, sólo sirvió para desviarse de la solución acertada. Parecía evidente, ya a la altura de 1740, que el asiento de negros no era beneficioso sin la carga suplementaria de mercancía ilegal. ${ }^{101}$

95 Debemos comprobar si la idea de la Gran Armada aparece ya en la primera edición de 1740 o tal vez fue añadida en las reediciones de 1762 y 1775 , realizadas por el propio autor, y que puedan justificar, de alguna manera, el despropósito del proyecto.

96 Dantini, 1741, I, 53r.

97 Malamud, 1986, 31.

98 Dantini, 1741, I, 49r-52v.

99 Ibidem, IV, 11-15.

100 Fisher, 1992, 141; Malamud, 1986, 51, en especial nota 9 para un balance historiográfico hasta 1986.

101 Hilton, 1980, 136, con aparato bibliográfico en 172-193. 


\section{Epílogo. Hacia el fin de las negociaciones (1741-1750)}

En el plano ministerial, a partir de 1741, la actividad gubernativa se centró en figuras clave como Campillo, Carvajal y Ensenada, ${ }^{102}$ fase que se cerró, para el caso que nos ocupa, con el acuerdo del equivalente el 5 de octubre de 1750. En este sentido las directrices políticas fueron, en apariencia, claras y unidireccionales, lo que favorece el análisis de los acontecimientos.

Desde la óptica comercial los años 1739-1754 abren y cierran una larga etapa intermedia en el desarrollo del comercio colonial del siglo XVIII. La primera fecha corresponde al inicio de la guerra contra Inglaterra (17391748), y el año 1754 a los antecedentes inmediatos de la primera flota organizada a Nueva España.

Tras unas tensas relaciones, se iniciaba en 1739 la guerra contra Inglaterra ${ }^{103}$ que empató con la de Sucesión austriaca (1740-1748). ${ }^{104} \mathrm{El}$ cambio en la situación internacional obligó a la implantación del sistema de registros sueltos y al abandono de las ferias comerciales. ${ }^{105}$

Lo que en principio parecía una buena solución propiciada por los acontecimientos deparó unos resultados negativos por ser la mayor parte de la mercancía, navíos, tripulación, etc. de procedencia extranjera.

Mientras las flotas estuvieron ausentes no se pudo desarrollar en la práctica el «chantaje comercial» al que estaban sometidos y acostumbrados los comerciantes, y se alargaban el número de intercambios pero no la cantidad total de mercancía, entre otros fenómenos negativos para los intereses particulares de los comerciantes. Además, aunque el sistema de los registros sueltos era más competitivo no se logró reducir el contrabando extranjero, centrado en la zona de Buenos Aires y en la Colonia de Sacramento. ${ }^{106}$

102 Sobre los gobiernos de Campillo, Carvajal y Ensenada tenemos recientes obras, que nos evitan tener que relatar los principales acontecimientos políticos, y que han sido citadas en nota 1,2 y 3 .

103 Sobre la guerra contra Inglaterra de 1739 se pueden consultar las obras de Hilton, 1980, 288; Lynch 1991, 126.

104 La guerra de Sucesión austriaca está pendiente de una revisión para el caso español.

105 Sobre el sistema de ferias puede consultarse las obras de Real Díaz, 1959, y Pérez Herrero, 1983.

106 Sobre los aspectos comerciales con Buenos Aires y el contrabando de la Colonia de Sacramento puede consultarse Céspedes del Castillo, 1947; Villalobos, 1986; y más recientemente Téllez Alarcia, 2008. 
Todo ello produjo dos efectos: el sistema de registros sueltos necesario por la guerra contra Inglaterra hizo que fracasara el intento de regular la Carrera de Indias fuera de España; y el otro, que finalizada la guerra se constató la necesidad de regresar al método tradicional.

Como consecuencia la Monarquía tuvo que reanudar la política interna del comercio colonial después del tratado de Aquisgrán. A este efecto responde la Junta Extraordinaria de 1750, y sus deliberaciones sobre el comercio colonial. A partir de esta fecha el sistema tradicional de flotas y galeones salió tocado pero no hundido. Desde el punto de vista administrativo se conformó el Virreinato de Nueva Granada (1739), y se permitió remitir —el 20 de junio de 1749 — con libertad el dinero americano para la adquisición específica de mercancías.

El sistema de registros sueltos, buscado o no por la Monarquía, va a constituir uno de los elementos dinamizadores del rígido monopolio gaditano. Bien es cierto que no va a presentar ninguna novedad legislativa, ya que quedaron bien establecidos desde los primeros años del comercio con América, pero será el único medio, junto a las compañías privilegiadas, de ponerse en contacto con América. El carácter accidental de la masiva utilización de los registros sueltos ha sido destacado por García Baquero, ${ }^{107}$ quien marcó el período 1739-1754 como la etapa generalizada en el uso de este sistema, pero sus beneficios y perjuicios, dependiendo de quién hablemos - Corona o Consulado-, ha merecido la reflexión de Delgado Rivas. ${ }^{108}$

$\mathrm{Al}$ finalizar la guerra se abre un período muy interesante de debate. $\mathrm{Al}$ no ser absolutamente necesario este sistema de intercambio se van a estudiar las pautas que deben regir ahora el sistema comercial con América.

Esta misión estuvo a cargo de la Junta de 1750, que propondrá la continuación de los registros sueltos para Perú, y la vuelta al sistema de flotas para Nueva España en 1754. A partir del 11 de octubre de 1754 quedó de nuevo restaurado el sistema de flotas para Nueva España, a pesar de que la primera expedición no fue iniciada hasta el 11 de febrero de 1757. La reglamentación de la feria de Jalapa, la exención del pago de alcabala, y toda la reglamentación sobre los rezagos y mercancía no vendida, no pudo evitar el fracaso de una flota donde los mercados estaban saturados. ${ }^{109}$

107 García Baquero, 1976, 165-174.

108 Delgado Rivas, 2007, 157.

109 Walker, 1979, 271. 
La Junta Extraordinaria presidida por Ensenada debía su formación a dos hechos principales: el fin de la guerra con Inglaterra y Sucesión austriaca, y las quejas del comercio gaditano, mexicano y peruano. El final de estas dos guerras y la política de equilibrio llevan a realizar un balance del sistema comercial con América, principalmente el tema de los sistemas de navegación. Estos balances que los políticos someten a la actuación comercial en América no eran desconocidos.

La Carrera de Indias venía practicando tradicionalmente el uso de flotas y galeones para el comercio con Nueva España y Tierra Firme. Como hemos visto a raíz de la guerra con Inglaterra de 1739 se aumentó el sistema de registros sueltos. Pero una vez acabadas estas guerras se pretendía hacer balance de estos medios y lograr establecer las nuevas pautas de intercambio.

Los miembros de esta Junta Extraordinaria presidida por Ensenada eran Alonso García, Andrés del Hoy, Manuel Clemente Rodríguez, Nicolás del Vasto, Nicolás Macé y Jacinto José de Barrios. El fin era «debatir el mejor medio de poner fin al desorden comercial del que todos se quejaban». ${ }^{110}$ Las deliberaciones se realizaron entre los miembros de la Junta y de las opiniones de otras fuentes: comerciantes, hombres de negocios, funcionarios, intereses particulares de Consulados, etc. Al final fue una postura intermedia la que prevaleció. ${ }^{111}$ Por un lado las ideas de libre comercio de José del Campillo no fueron aceptadas; ${ }^{112}$ tampoco lo fueron la creación de compañías, ya fueran estas generales o por provincias, como defendieron Marcelo Dantini en 1741 y José de Carvajal en 1743.

En un primer acuerdo se propuso el restablecimiento de las flotas a Nueva España, pero sin especificar ni el número de toneladas ni la frecuencia de las salidas. El 11 de octubre de 1754 se anunció la vuelta al sistema de flotas cada dos años, sin participación de navíos de registro. A esto se añadía el retorno al sistema de feria en Jalapa, la exención del pago de alcabala, la prohibición de sacar la mercancía hasta la finalización de la feria, y una reglamentación específica para los comerciantes rezagados en las anteriores flotas o registros. En realidad la flota no partió hasta el 11 de febrero de 1757 por una saturación de mercancía en el mercado novohispano.

110 Ibidem, 265 y ss. Sus componentes ya los citaba Real Díaz, 1959, 260, nota número 6.

111 Para el marqués de la Ensenada el sistema de navegación más adecuado era: «Concederles la libre navegación [a los extranjeros] como lo piden, no es posible sin abandonar las Indias; restringirla, como pretendemos, tampoco es practicable, aunque fuera justo, con que entre los dos extremos se ha de procurar alguna senda que nos lleve al término deseado».

112 Delgado, 2009, 44-50. 
Perú ofrecía otras condiciones. Su mercado estaba bien abastecido, las defensas de Portobelo estaban todavía sin levantar, etc. Esto obligó a pensar en una posible solución con la utilización de Buenos Aires como puerto de entrada de las mercancías. Esta propuesta finalmente fue rechazada por la inadecuada constitución del puerto para la recepción de un masivo número de navíos, por una falta de madera para reparación de los navíos y por establecer la feria en Mendoza, lugar muy alejado de Buenos Aires.

Como bien explica Walker no debemos olvidar entre las razones del fracaso del cambio de galeones hacia Buenos Aires la rivalidad con Perú, ya que desde ese puerto se podía actuar con facilidad sobre el comercio de Charcas y del Alto Perú quitando poder a los comerciantes, incluso la riqueza mineral podría salir hacia Buenos Aires por esa vía. En definitiva se llegó a la conclusión de continuar con los navíos de registros para esta zona de Tierra Firme. ${ }^{113}$

Entre la acción política y la reflexión teórica está la figura de José de Carvajal y Lancaster (1743-1754), quién intentó poner en práctica su ideario político-económico. Sus tres importantes aportaciones en el campo teórico son el Testamento político de 1745, la Representación de 1752 y Mis pensamientos de $1753,{ }^{114}$ amén de su correspondencia epistolar. Sobre la base de estas aportaciones vamos a intentar reconstruir el ideario de Carvajal sobre la presencia extranjera en el comercio colonial.

La fuente bibliográfica clásica de Ozanam sigue siendo básica para acceder a la correspondencia entre Carvajal y el duque de Huéscar. Para nuestro trabajo esta fuente cuenta con varios problemas: la correspondencia se centra más en temas cercanos a las relaciones internacionales que a los asuntos de economía o comercio colonial; y el período que abarca es de tres años, entre 1746 y 1749.

Sin embargo, a lo largo de su correspondencia descubrimos un interés por dos temas claves tanto de la política internacional como de la nacional: el navío de permiso y el asiento de negros. Así Carvajal llega a escribir a Huéscar sobre el interés de acabar con el asiento, ya que:

Si quedamos sin poner en uso el asiento de negros cesando la guerra, difícilmente nos lo sacarán en un congreso, y el librarnos de él es la mayor importancia de Indias. ${ }^{115}$

113 Sobre esta rivalidad entre Buenos Aires y Perú véanse las obras de Céspedes, 1947 y Walker, 1979.

114 Delgado Barrado, 2001.

115 Carvajal a Huéscar, 29 de mayo de 1747, en Ozanam, 1975, 163. 
Sobre el navío de permiso hacia observar a su receptor:

en cómo pongo lo de la Libre Navegación, que es con sus mismas palabras, que son las que clama el pueblo, y en viéndolas se aquietará. Los doctos del vasquense [Villarias] temen ésa sobre todo, y yo temo más el asiento de negros y navío de permiso. Verdad es que la liberta[d] de uno y otro no la pido, que la pago, y en realidad se acabó ya su tiempo y con el arbitrio del puerto franco dejo esperanzas de ganar mucho a Ingleses. ${ }^{116}$

Es también curiosa la respuesta de Huéscar:

Soy poco sastre para decidir sobre materias de Libre Navegación y preferir las ventajas de ésta o del Asiento de Negro, pero en mi corto entender aventuramos poco en convenir en la libre navegación según la propones, respecto de que es importante evitarla y perderíamos mucho si el asiento de negros y el navío del permiso continuasen. ${ }^{117}$

Otro personaje, Luis Dumontier, escribe en una época donde los acuerdos diplomáticos tras la guerra con Inglaterra (1739-1748), la polémica en la diplomacia española entre Carvajal y Ensenada, etc., evidencia un transfondo muy complejo y cargado de intencionalidad política.

Evidentemente su obra no es gratuita al tratar el tema del asiento y navío en torno a 1749. En la atmósfera estaban el tratado de Aquisgrán y la futura Junta Extraordinaria de 1750. Es decir, su obra está enmarcada en un ambiente internacional y nacional donde se estaban debatiendo o se debatirán contenidos como la situación de territorios perdidos por la Corona (Gibraltar y Menorca), el sistema de navegación a emplear tras la guerra con Inglaterra, entre otros.

Sobre el navío del asiento era muy crítico: «El navío de asiento que tenía concedido la Inglaterra era la ruina y la destrucción del comercio de España». ${ }^{118}$

El mal no estaba sólo en el comercio de negros, sino en las mercancías que transportaba:

El abuso y el fraude no se limitaban al sólo porte del navío que pasaba de más de la mitad de lo que debía ser, pero con el pretexto de avituallar, refrescar dicho navío y traer provisiones a toda la gente de la nación inglesa que mantenía entonces, venía de cuando en cuando una balandra de más de 900 toneladas de porte, cargada de mercaderías. ${ }^{119}$

116 Carvajal a Huéscar, 18 de marzo de 1747, en Idem.

117 Huéscar a Carvajal, 5 de abril de 1747, en Idem.

118 Dumontier, 1749, 186r.

119 Idem. 
El autor estaba al tanto de las negociaciones para trata el pago de un equivalente a los ingleses, y era contrario a pagar cualquier cantidad por retirar estos privilegios a Inglaterra, ya que:

El Monarca de España, y todos sus fieles vasallos, no deberían jamás consentir, ni permitir, por concesión de ningún tratado se conceda el libre comercio de sus Indias a ninguna nación, pues sería hacer dependiente de ella, y concederle un derecho sobre sus dominios, ni menos rescatar semejante privilegio con el convenio de pagar anualmente ni tampoco una vez tantum ninguna cantidad de dinero, que con este se adquiriría el título de tributario y se manifestaría un temor evidente de la misma nación, de la cual se compraría la amistad a fuerza de dinero. ${ }^{120}$

El ataque contra los ingleses era continuado:

si a cualquier nación se debe prohibir el comercio de las Indias, con particularidad debe ser la inglesa, por las muchas experiencias que se tienen del malísimo uso que ha hecho de los tesoros inmensos que ha sacado de las Indias.

Y para aumentar esa inquina recurre incluso a recordar al monarca español la posición de los ingleses en contra de Felipe $\mathrm{V}$ en la pasada guerra de Sucesión y la ruinosa flota de 1723.

Y como ejemplo de cómo el asiento y navío se habían convertido en elementos de negociación en la política internacional de los estados, propuso un intercambio de piezas:

Pretenden obtener el gran beneficio del comercio de Indias y aún se quieren reservar la posesión de Gibraltar y de Puerto Mahón; ofreciesen para obtener el comercio de las Indias la restitución de estas dos plazas, a lo menos de una, y entonces se observaría en su proceder algo de tratable, y en todo caso se podría conceder una cosa para obtener la otra.

\section{La idea es reforzada más adelante:}

no conceder con ningún pretexto el navío de asiento a los ingleses, ni absolutamente ningún comercio a las Indias, si primero no restituyen las dos citadas plazas. Esto debería ser el preliminar de tratado del comercio de las Indias.

La cuestión de Gibraltar, de Menorca - Mahón-, el asiento de negros y el navío de permiso eran las lacras de la restauración de la Monar-

120 Ibidem, $185 \mathrm{v}$. 
quía Hispánica, y su eliminación o recuperación eran vitales en las negociaciones internacionales.

José Gutiérrez de Rubalcava, a mediados del siglo XVIII, esbozaba un panorama de los problemas que aquejaban a la Monarquía. ${ }^{121} \mathrm{El}$ aumento de la población en América llevó a un incremento del consumo, que las manufacturas españolas no podían abastecer. Por ello se recurrió a las manufacturas y productos extranjeros.

Sin embargo, uno de los males del comercio era la intromisión extrajera en el comercio con Indias. Los extranjeros habían aprovechado los años de conflicto bélico para penetrar en estos mercados, ejerciendo el comercio ilícito, acciones piráticas y corsarias, y creando pequeñas colonias como plataformas para comerciar con la América hispánica.

Según Rubalcava el asiento de negros era uno de los medios empleados para promover este comercio ilícito, ya que esta concesión comercial no estaba teniendo beneficios, salvo por esta intromisión en los mercados comerciales españoles, que:

padece mucho cuando se le introduce desde fuera lo que perturba su armonía en aquellos parajes, o se les saca lo que debe ser parte precisa de los contratos de su general tráfico, muchas veces perjudicado por invertirse su método y regular curso con la falta de caudales o sobra de géneros para la debida igualdad de las ventas. ${ }^{122}$

Este era uno de los problemas del sistema de las ferias novohispanas, ya que mal funcionaban durante los periodos de conflictos bélicos, se interrumpían los intercambios de particulares, aumentaba la presencia extranjera, y perjudicaba a los comerciantes. En todo caso se retenían las mercancías el tiempo necesario para controlar los precios - dependiendo si eran almaceneros o flotistas-. Sin embargo, el sistema del «chantaje comercial» de los comerciantes españoles en América quedaba destruido con la arribada de mercancías extranjeras proveniente del asiento de negros y el navío de permiso, que a su vez ejercían un nuevo chantaje comercial.

121 José Gutiérrez de Rubalcava fue profesor de Derecho Canónico y Civil y asesor de Marina en la comisión de Montes y Plantíos del Departamento de Cádiz, y era sobrino de Alejo Gutiérrez de Rubalcava, presidente del Despacho de la Secretaría de la Presidencia del Tribunal y Casa de la Contratación a las Indias. Sobre la familia Rubalcava véase AHN, Universidades, 665, exp. 74. José Gutiérrez escribió un compendio impreso sobre el comercio colonial, Gutiérrez, 1750. El libro estaba dedicado al marqués de la Ensenada.

122 Gutiérrez, 1750, 230-231. 


\section{Conclusiones}

Hemos demostrado como existe un pensamiento político-económico español sobre el asiento de negros y el navío de permiso entre 1701 y 1750. Muchos de los autores son anónimos, es decir, no sabemos quiénes fueron, de los que conocemos sus nombres desconocemos los rasgos principales de su vida, formación y filiación a grupos de poder, algunos de ellos fueron extranjeros, seguramente con distintos intereses en España. Además, por si esto fuese poco, quedan espacios administrativos y burocráticos sin revisar, como algunas de las juntas citadas — sólo hemos analizado con mayor profundidad, como ejemplo, las Junta de Medios_ o documentación de secretarías y despachos, la vía reservada, el padre confesor, etc. El quién es quién del reformismo borbónico, y más en la primera mitad del siglo XVIII, que sigue siendo una asignatura pendiente para algunos personajes y coyunturas.

Hemos intentando ajustar diversas cronologías: los acontecimientos políticos nacionales e internacionales, los vaivenes comerciales, junto a periodos de paces, guerras, treguas, negociaciones, etc., incluso señalando las fases donde fueron interrumpidos los intercambios del asiento y navío, para ver relaciones entre reflexiones teóricas y acciones prácticas de gobierno, mayor presión política o dejadez.

Son numerosos los flecos del presente trabajo, dada la complejidad de analizar el pensamiento político-económico español sobre el asiento de negros y navío de permiso durante un largo periodo de tiempo, que corresponde a la primera mitad del siglo XVIII.

Para completar esta visión habría que atender a varios planos de investigación. El primero sería constatar en las fuentes documentales británicas los resultados prácticos de la compañía del asiento y las cuentas del navío, así como las actas de las diversas juntas de accionistas, teniendo presente los diversos planos de intereses, entre comerciantes y responsables políticos, incluidos los propios monarcas. El segundo sería precisar en detalle las negociaciones de Utrecht y su evolución hasta la desaparición del asiento de negros y el navío de permiso, precisando qué cosa son y qué características tienen, así como saber quiénes son los protagonistas de los acontecimientos. Para ello es fundamental seguir profundizando en cómo y quién dirige el sistema de gobierno de la Monarquía Hispánica de la primera mitad del siglo XVIII, donde la mayoría de las preguntas siguen, como hemos señalado, sin respuestas.

Recibido el 25 de mayo de 2014

Aceptado el 4 de febrero de 2015 


\section{Bibliografía}

Alsedo y Herrera, Dionisio de: Piraterías y agresiones de los ingleses y de otros pueblos de Europa en la América española... [1740]. Publicadas por Justo Zaragoza (1883), Edición de José María Sánchez Molledo, Sevilla, Editorial Renacimiento, 2005a.

Alsedo y Herrera, Dionisio de: Descripción de los tiempos de España en el presente décimo octavo siglo [1763], Edición de José María Sánchez Molledo, Madrid, Ediciones Polifemo, 2005b.

Anes, Gonzalo: Restablecimiento de las fábricas y comercio español (1740), Madrid, Ministerio de Hacienda, 1992.

Bély, Lucien: «Les negociations franco-espagnoles pendant la Guerre de Succession d'Espagne», en León Sanz, Virginia (coord.), «1713. La Monarquía de España y los Tratados de Utrecht», Cuadernos de Historia Moderna, Anejo XII, Madrid, 2013, 61-76.

Bitar Letayf, Marcelo: Economistas españoles del siglo XVIII: sus ideas sobre la libertad del comercio con Indias, Madrid, Cultura Hispánica, 1968 [México, Instituto Mexicano de Comercio Exterior, 1976].

Carrera Pujal, Jaime: Historia de la Economía Española, Barcelona, Bosch, 19431947.

Castellano Castellano, Juan Luis: Gobierno y poder en la España del siglo XVIII, Granada, Editorial Universitaria de Granada, 2006.

Castro Monsalve, Concepción de: A la sombra de Felipe V: José de Grimaldo, ministro responsable (1703-1726), Madrid, Marcial Pons, 2004.

Céspedes del Castillo, Guillermo: Lima y Buenos Aires: repercusiones económicas y políticas de la creación del Virreinato del Plata, Sevilla, Escuela de Estudios Hispano-Americanos, 1947.

Colmeiro, Manuel: Biblioteca de los economistas españoles de los siglos XVI, XVII y XVIII, Madrid, Publicaciones de la Real Academia de Ciencias Morales y Políticas, s.f.

Correa Calderón, Enrique: Registro de arbitristas, economistas y reformadores españoles (1500-1936). Catálogo de impresos y manuscritos, Madrid, Fundación Universitaria Española, 1981.

Crespo Solana, Ana: La Casa de la Contratación y la Intendencia General de la Marina de Cádiz (1717-1730), Cádiz, Servicio de Publicaciones de la Universidad de Cádiz, 1996.

Danvila y Burguero, Alfonso: Luisa Isabel de Orleans y Luis I, Madrid, Librería de Fernando Fe, 1902.

Danvila y Burguero, Alfonso: El reinado relámpago. Luis I y Luisa Isabel de Orleans, 1707-1742, Madrid, Espasa-Calpe, 1952 [Madrid, Alderabán, 1997].

Dedieu, Jean-Pierre: «El aparato de gobierno de la Monarquía española en el siglo XVIII», en Pérez Sarrión, Guillermo (ed.): Más Estado y más mercado. 
EN TORNO A UTRECHT Y AQUISGRÁN: EL PENSAMIENTO POLÍTICO-ECONÓMICO

Absolutismo y economía en la España del siglo XVIII, Madrid, Sílex, 2011, 53-73.

Delgado Barrado, José Miguel: El proyecto político de Carvajal: pensamiento y reforma en tiempos de Fernando VI, Madrid, CSIC, 2001.

Delgado Barrado, José Miguel: Aquiles y Teseos. Bosquejos del reformismo borbónico (1701-1759), Granada, Editorial Universitaria de Granada, 2007.

Delgado Barrado, José Miguel: «Proyectos de reforma de la Real Hacienda bajo Felipe V. El caso de Alejandro de la Vega (1713-1739)», en Bravo Caro, J. J. y Villas Tinoco, S. (eds.), Tradición versus innovación en la España Moderna, Málaga, Universidad de Málaga, 2009, I, 395-408.

Delgado Barrado, José Miguel: «Francisco Máximo Moya Torres y Velasco (Jaén, 1680-1685?-¿?)», en Sánchez Lissen, R. (coord.), Economía y economistas andaluces (siglos XVI al XX), Madrid, Ecobook, 2013, 183-193.

Delgado Rivas, J. M.: Dinámicas imperiales (1650-1796). España, América y Europa en el cambio institucional del sistema colonial español, Barcelona, Edicions Bellaterra, 2007.

Desos, Catherine: La vie du R. P. Guillaume Daubenton, S.J. (1648-1723). Un jésuite français à la cour d'Espagne et à Rome, Córdoba, Universidad de Córdoba, 2005.

Desos, Catherine: Les Français de Philippe V. Un modèle Nouveau pour gouverner l'Espagne (1700-1724), Strasbourg, Press Universitaires de Strasbourg, 2009.

Dubet, Anne: «Administrar los gastos de la guerra: Juan Orry y las primeras reformas de Felipe V (1703-1705)», en Guimerá Ravina, Agustín y Peralta Ruiz, Víctor (coords.), El equilibrio de los Imperios: de Utrecht a Trafalgar, Actas de la VIII Reunión Científica de la Fundación Española de Historia Moderna, Madrid, 2-4 de junio de 2004, vol. II, Madrid, Fundación Española de Historia Moderna, 2005, 483-502.

Dubet, Anne: Un estadista francés en la España de los Borbones. Juan Orry y las primeras reformas de Felipe V (1701-1706), Biblioteca Nueva, Madrid, 2008.

Duriols, Jean-Paul (ed.): Mémories du Mexique. Le manuscrito de Jean de Monségur, 1707-1709, París, Chandeigne, 2002.

Elorza, Antonio: «Representación universal...», Revista de Occidente, 85, 1970, 124-126.

Escudero, José Antonio: Los secretarios de Estado y del Despacho (1474-1724), Madrid, Instituto de Estudios Administrativos, 1969.

Fayard, Janine: Los miembros del Consejo de Castilla (1621-1746), Madrid, Siglo XXI, 1982.

Fernández Albadalejo, Pablo: «El decreto de suspensión de pagos de 1739: análisis e implicaciones», Moneda y Crédito. Revista de Economía, Madrid, 142, 1977, 51-85. 
Fernández Durán, Reyes: Gerónimo de Uztáriz (1670-1732). Una política económica para Felipe V, Madrid, Minerva, 1999.

Fernández Durán, Reyes: «Bernardo de Ulloa y Sosa», en Perdices de Blas, Luis y Sánchez Hormigo, Alfonso (coords.), 500 años de economía a través de los libros españoles y portugueses, Madrid, Biblioteca Histórica Marqués de Valdecilla/Universidad Complutense, 2007a, 66.

Fernández Durán, Reyes: «Jerónimo de Uztáriz», en Perdices de Blas, Luis y Sánchez Hormigo, Alfonso: 500 años de Economía a través de los libros españoles y portugueses, Biblioteca Histórica Marqués de Valdecilla, Madrid, 2007b, 63.

Fernández Durán, Reyes: La corona española y el tráfico de negros: del monopolio al libre comercio, Madrid, Ecobook, 2011.

Fragnito, G. (dir.): Elisabetta Farnese, principessa di Parma e regina di Spagna, Roma, Viella, 2009.

Frey, Linda y Frey, Marsha (eds.): The Treaties of the War of the Spanish Succession. An Historical and Critical Dictionary, London, Greenwood Press, 2005.

García Baquero, Antonio: Cádiz y el Atlántico (1717-1778). El comercio colonial español bajo el monopolio gaditano, Sevilla, Escuela de Estudios HispanoAmericanos, 1976.

García Ruipérez, Mariano: «El pensamiento económico ilustrado y las compañías de comercio», Revista de Historia Económica, 4-3, 1986, 521-548.

Gómez Urdáñez, José Luis: El proyecto político de Ensenada, Madrid, Editorial Milenio, 1996.

Gómez Urdáñez, José Luis: Fernando VI, Madrid, Arlanza, 2001.

González Beltrán, Jesús Manuel: «Un ejército armado de pluma y papel sellado. Una aproximación a la burocracia del siglo XVIII», en Aranda Pérez, Francisco José (coord.), Letrados, juristas y burócratas en la España Moderna, Cuenca, Ediciones de la Universidad de Castilla-La Mancha, 2005, 435-478.

Gutiérrez de Rubalcava, José: Tratado histórico, político y legal del comercio de las Indias Occidentales, pertenecientes a los Reyes Católicos, conforme al tiempo de paz y guerra, en interpretación de las Leyes de la Nueva Recopilación a ellas. Primera parte. Compendio histórico del Comercio de las Indias desde su principio hasta su actual estado, Cádiz, Imprenta Real de Marina, 1750.

Hilton, Silvia-Lyn: Las Indias en la diplomacia española, 1739-1759, Madrid, Universidad Complutense, 1980.

Hussey, Roland Dennis: La Compañía de Caracas, 1728-1784, Caracas, Banco Central de Venezuela, 1962.

Larruga y Boneta, Eugenio: Historia de la Real y General Junta de Comercio, Moneda y Minas y dependencias de Extranjeros y colección íntegra de los reales decretos, pragmáticas..., Madrid, 1788. 
López Arandia, María Amparo: «Velando por el ánima del rey católico. Gabriel Bermúdez, confesor de Felipe V (1723-1726)», en Martínez Millán, J.; Pizarro Llorente, H.; Jiménez Pablo, E.: Los jesuitas. Religión, política y educación (siglos XVI-XVIII), Madrid, Polifemo, 2012, vol. I, 255-278.

López-Cordón, María Victoria; Pérez Samper, María Ángeles; Martínez de Sas, María Teresa: La casa de Borbón: familia, corte y política, Madrid, Alianza Editorial, 2000.

Lynch, John: La España del siglo XVIII, Barcelona, Crítica, 1993.

Malamud Rikles, Carlos: Cádiz y Saint Malò en el comercio colonial peruano (1698-1725), Cádiz, Diputación Provincial, 1986.

Martínez Millán, José; Camarero Bullón, Concepción; Luzzi Traficante, M. (coords.): La Corte de los Borbones. Crisis del modelo cortesano, Madrid, Polifemo, 2013.

Martínez Shaw, Carlos: Cataluña en la Carrera de Indias 1680-1756, Barcelona, Crítica, 1981.

Martínez Shaw, Carlos y Alfonso Mola, Marina: Felipe V, Madrid, Arlanza Ed., 2001.

Mesnager, Nicolás: Espions et ambassadeurs au temps de Luois XIV, París, Fayard, 1990.

Molas i Ribalta, Pere: «Instituciones administrativas y grupos sociales en la España del siglo XVIII: las juntas de comercio», en Actas de las I Jornadas de Metodología Aplicada de las Ciencias Históricas, Universidad de Santiago de Compostela, 1975, vol. 3, 795-802.

Molas i Ribalta, Pere: «La Junta General de Comercio y Moneda: la institución y los hombres», Hispania, Revista española de Historia, 38, extra 9, Madrid, 1978, 1-38.

Molas y Ribalta, Pere: «Dos proyectos de reforma de la Junta de Comercio: Torrehermosa y Sartine (1720-1721)», en José Checa Beltrán y Joaquín Álvarez Barrientos (coord.), El Siglo que llaman Ilustrado, Madrid, CSIC, 1996.

Molina Cortón, Juan: Reformismo y neutralidad. José de Carvajal y la diplomacia de la España preilustrada, Mérida, Editora Regional de Extremadura, 2003.

Moro, Gerardo: Informe en derecho sobre la Compañía del Real Asiento de la Gran Bretaña establecida para la introducción de esclavos negros en estas Indias..., México, 1724, BNE, 3/26104.

Moya Torres y Velasco, Francisco M. de: Manifiesto Universal de los males envejecidos que España padece, Edición y estudio preliminar de Antonio Domínguez Ortiz, Col. Clásicos del Pensamiento Económico Español, Madrid, Instituto de Cooperación Iberoamericana/Quinto Centenario/Antoni Bosch Ed./Instituto de Estudios Fiscales, 1992.

Mur Raurell, Ana: Diplomacia secreta y paz. La correspondencia secreta de los embajadores españoles en Viena. Juan Guillermo Ripperdá y Luis Ripperdá (1724-1727), Madrid, Ministerio de Asuntos Exteriores, 2011. 
Ozanam, Didier: La diplomacia de Fernando VI: correspondencia reservada entre D. José de Carvajal y el duque de Huéscar, 1746-1749, Madrid, CSIC, 1975. Perdices de Blas, Luis y Sánchez Hormigo, Alfonso (coords.): 500 años de economía a través de los libros españoles y portugueses, Madrid, Biblioteca Histórica Marqués de Valdecilla/Universidad Complutense, 2007.

Pérez Samper, María Ángeles: Isabel de Farnesio, Barcelona, Plaza \& Janes, 2003. Pérez-Mallaína, Pablo E.: Política naval española en el Atlántico, 1700-1715, Sevilla, Escuela de Estudios Hispano-Americanos, 1982.

Rahola y Tremols, Federico: Comercio de Cataluña con América en el siglo XVIII, Barcelona, 1931.

Real Díaz, José Joaquín: «Las ferias de Jalapa», Anuario de Estudios Americanos, XVI, Sevilla, 1959, 167-314.

Sánchez Molledo, José María: El pensamiento arbitrista en el reino de Aragón en los siglos XVI y XVII, Madrid, 1998.

Sánchez Molledo, José María: «Arbitristas aragoneses en el siglo XVIII», Torre de los Lujanes. Boletín de la Real Sociedad Económica Matritense de Amigos del País, 38, Madrid, 1999, 221-242.

Taxonera, Luciano de: El cardenal Julio Alberoni: forjador de una nueva España en el siglo XVIII, Madrid, Editora Nacional, 1945a.

Taxonera, Luciano de: El Duque de Riperda, el gobernante aventurero, Madrid, Gran Capitán, 1945b.

Téllez Alarcia, Diego: La manzana de la discordia. Historia de la Colonia del Sacramento desde la fundación portuguesa hasta la conquista por los españoles (1677-1777), S.L. Rubeo, 2008.

Téllez Alarcia, Diego: Absolutismo e ilustración en la España del siglo XVIII: el despotismo ilustrado de D. Ricardo Wall, Madrid, Fundación Española de Historia Moderna, 2010.

Vázquez Gestal, Pablo: Felipe V, Isabel de Farnesio y la identidad de la monarquía (1700-1729), Madrid, Marcial Pons, 2013.

Vilar, Juan Bautista: Un viajero holandés del siglo XVIII: el duque de Ripperdá en Marruecos y Túnez, Madrid, Información y Revistas, 1985.

Vilar, Pierre: Le Manual de la Comapnya Nova de Gibraltar, 1709-1723, París, SEVPEN, 1962 [edición en castellano, Reus, 1990].

Vilar, Pierre: Cataluña en la España Moderna, Barcelona, Crítica, 1979-1988.

Vilar, Pierre: Crecimiento y desarrollo: economía e historia, reflexiones sobre el caso español, Barcelona, Planeta-Agostini, 1992.

Villalobos, Sergio: Comercio y contrabando en el Río de la Plata y Chile, 17001811, Buenos Aires, Eudeba, 1986.

Walker, Geoffrey J.: Política española y comercio colonial: 1700-1789, Barcelona, Ariel, 1979. 